\title{
A purely penoscrotal approach: Reservoir placement of an inflatable penile prosthesis (IPP) in an orthotopic neobladder patient. Case report
}

\author{
Cumhur Yeşildal, Ahmet Tevfik Albayrak, Abdullah Hizir Yavuzsan, Musab ilgi, Sinan Levent Kireççi \\ Department of Urology, Sisşli Hamidiye Etfal Training and Research Hospital, University of Health Science, Istanbul, Turkey.
}

\begin{abstract}
Summary Introduction: The inflatable penile prosthesis (IPP) is the last step in drug-resistant erectile dysfunction treatment. IPP implantation can be challenging, especially following a cystoprostatectomy with an orthotopic neobladder. There is no consensus about surgical techniques for placement of an IPP reservoir in such patients. In this paper, we present a case of an IPP and reservoir placement with a single penoscrotal incision.

Case: A 55-year-old patient, who underwent radical cystoprostatectomy with an orthotopic neobladder seven years ago, presented with severe erectile dysfunction. His oncologic status was stable, and he was in remission. He also had high blood pressure and took medication for it. He previously used different medical treatments, such as oral phosphodiesterase-5 inhibitors (PDE5i), intraurethral prostaglandin E2 (PGE2) installations, and Trimix injections. As far as we know, he had no benefit from these treatments. A three-piece IPP was recommended. After a discussion of surgical techniques, we chose the penoscrotal approach, and the ectopic reservoir was placed through the inguinal canal, guided by a forefinger.

Results: The total operative time was 60 minutes, and the estimated blood loss was minimal. There were no perioperative complications. The patient was discharged on postoperative day one. He could start to use the IPP in the first month. His sexual and urinary functions were normal, and there was no abdominal bulging from the ectopic reservoir at the three-month follow-up.

Conclusions: In conclusion, ectopic placement of the reservoir through a single penoscrotal incision appears to be a safe and acceptable surgical technique for postoperative ED following a radical cystoprostatectomy with an orthotopic neobladder.
\end{abstract}

KEY WORDS: Penile prosthesis; Erectile dysfunction; Orthotopic neobladder.

Submitted 9 February 2019; Accepted 13 February 2019

\section{INTRODUCTION}

Although the retropubic and perivesical spaces are known to be the best locations for three-piece IPP reservoirs, the use of these locations becomes impossible with an underlying cause of fibrosis due to pelvic surgery, such as radical prostatectomy, cystectomy, or even radiotherapy to the pelvis.

As an alternative to these locations, ectopic reservoirs can be placed between the transverse fascia and the abdominal muscles (1-3). However, as far as we know, no one had attempted to place an IPP reservoir with a penoscrotal approach in a radical cystoprostatectomy patient with a neobladder. We describe a safe placement method for the reservoir of an IPP via a single penoscrotal incision in a neobladder patient who has a secondary erectile dysfunction due to a past radical cystoprostatectomy (Figure 1).

\section{CAse}

A 55-year-old bladder cancer patient, who had undergone radical cystoprostatectomy with an orthotopic Studer neobladder seven years ago, presented with severe erectile dysfunction (ED). He had already used medical treatments such as oral phosphodiesterase-5 (PDE5i) inhibitors, Trimix, and prostaglandin E2 (PGE2). He had hypertension and took medication. Our clinic recommended a three-piece inflatable penile prosthesis as an end-stage treatment. At that point, surgical techniques were discussed, and we agreed on the penoscrotal approach.

The ectopic reservoir was placed from the inguinal canal, guided by a forefinger. Then the posterior wall of the inguinal canal was pricked, and the internal obliques and transversal muscles were separated, followed by circumferential sweeping using the forefinger.

The Cloverleaf reservoir was established, filled with $65 \mathrm{~mL}$

\section{Figure 1.}

An abdominal cross-section of the 55-year-old patient, showing the orthotopic bladder formed seven years ago.

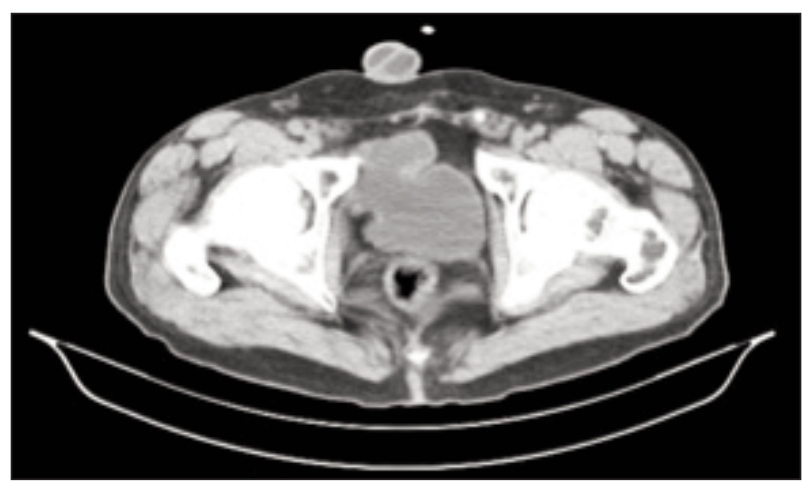


saline solution, and then evaluated for back pressure. Finally, a narrowing suture was placed at the orifice of the inguinal canal to prevent the reservoir from slipping downward.

\section{Discussion}

A surgeon should carefully plan how and where to place the IPP reservoir in ED patients with a neobladder. As we know, after radical cystoprostatectomy with an orthotopic neobladder, a significant part of the peritoneum cannot be closed. Therefore, a part of the small intestine can be found in the pelvic cavity. If the surgeon does not consider this possibility and tries to insert a reservoir
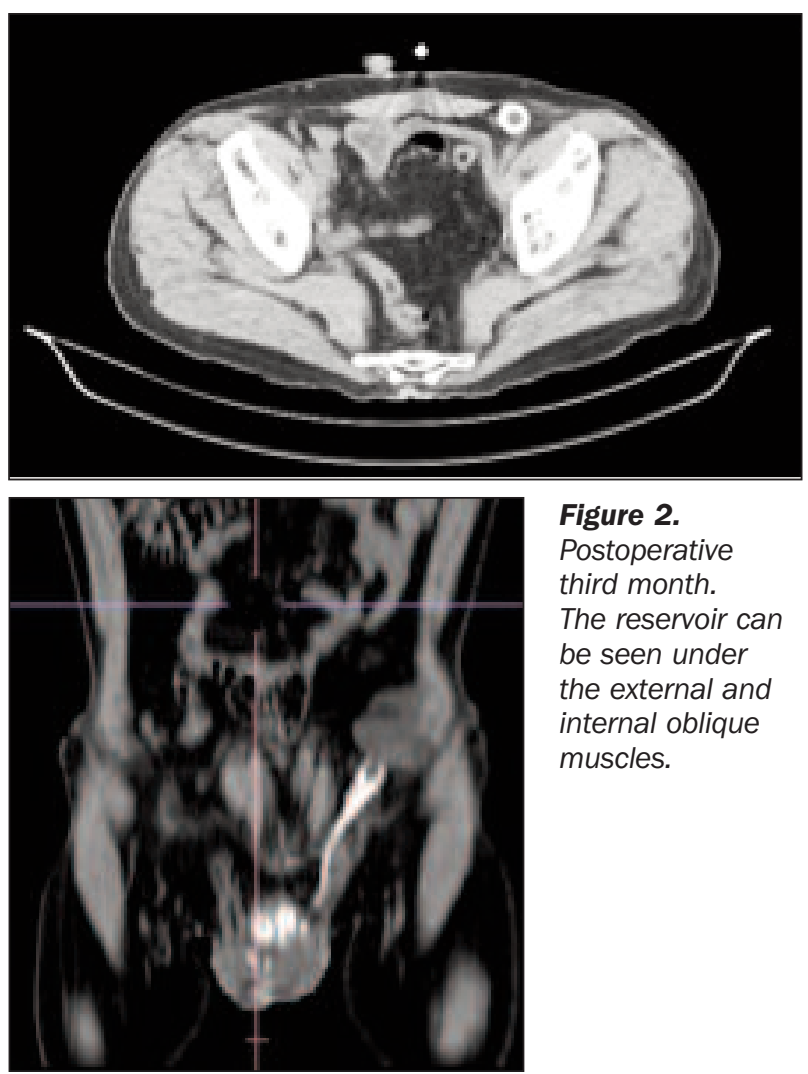

Figure 2.

Postoperative third month.

The reservoir can be seen under the external and internal oblique muscles.

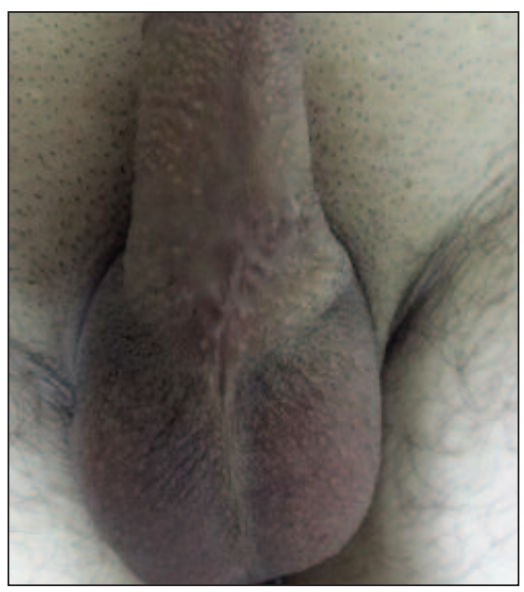

Figure 3.

Postoperative third month. Penoscrotal operation area. single incision. with classical methods such as scrotal or infrapubic incision, it may damage the neobladder, the intestines, and even the inferior epigastric vessels $(2,3)$.

There is one report that describes an alternative way to place the IPP reservoir (4). Jung Kwon Kim et al. placed the IPP reservoir with a separate longitudinal incision two fingerbreadths to the left and lateral to the umbilicus. Although this approach is feasible, it has no advantage against our technique since it is done with a secondary incision. In our procedure, we placed the IPP and its Cloverleaf reservoir using a single penoscrotal incision (Figure 2).

The total operative time was 60 minutes. There were no perioperative complications, nor was there more blood loss than expected.

On the fifteenth day after the surgery, we started to train the patient about how to use the IPP. We recommended abstaining from sexual intercourse for the first six weeks. He was able to begin using the IPP in the sixth week. His sexual and urinary functions were normal, and his sexual satisfaction was very high. There was no abdominal bulging from the ectopic reservoir at the three-month follow-up (Figure 3).

The ectopic placement of a flat reservoir using only a penoscrotal incision appears to be a safe and feasible surgical technique for postoperative ED following radical cystoprostatectomy with orthotopic neobladder.

\section{REFEREnCES}

1. Al-Enezi A, Al-Khadhari S, Al-Shaiji TF. Three-piece inflatable penile prosthesis: surgical techniques and pitfalls J Surg Tech Case Rep. 2011; 3:76-83

2. Perito PE, Wilson SK. Traditional (retroperitoneal) and abdominal wall (ectopic) reservoir placement J Sex Med. 2011; 8:656-9.

3. Morey AF, Cefalu CA, Hudak SJ. High submuscular placement of urologic prosthetic balloons and reservoirs via transscrotal approach J Sex Med. 2013; 10:603-10.

4. Kim JK, Cho MC, Ku Ja Hyeon, et al. Preperitoneal placement of an inflatable penile prosthesis reservoir for postoperative erectile dysfunction after radical cystoprostatectomy with orthotopic neobladder Investig Clin Urol. 2016; 57:364-366.

\section{Correspondence \\ Cumhur Yesildal, MD \\ c_yesildal@hotmail.com \\ Ahmet Tevfik Albayrak, MD atevfikalbayrak@gmail.com \\ Abdullah Hizir Yavuzsan, MD hiziryavuzsan@hotmail.com \\ Musab Ilgi, MD \\ ilgimusab@gmail.com}

Sinan Levent Kirecci, MD

sinankirecci@yahoo.com.tr

University of Health and Sciences Sisli Etfal Traning and Research Hospital Urology Department Halaskargazi Cad., Etfal Sk., 34371 Sissli//Istanbul (Turkey) 